\title{
Overcoming Statistical Helplessness and Developing Statistical Resilience in Learners: An Illustrative, Collaborative, Phenomenological Study
}

\author{
Sue Johnston-Wilder, Janet Goodall, Hani Almehrz \\ University of Warwick, Warwick, UK \\ Email: sue.johnston-wilder@warwick.ac.uk
}

How to cite this paper: Johnston-Wilder, S., Goodall, J., \& Almehrz, H. (2018). Overcoming Statistical Helplessness and Developing Statistical Resilience in Learners: An Illustrative, Collaborative, Phenomenological Study. Creative Education, 9, 1105-1122. https://doi.org/10.4236/ce.2018.97082

Received: May 7, 2018

Accepted: June 18, 2018

Published: June 21, 2018

Copyright ( $\odot 2018$ by authors and Scientific Research Publishing Inc. This work is licensed under the Creative Commons Attribution International License (CC BY 4.0).

http://creativecommons.org/licenses/by/4.0/

(c) (i) Open Access

\begin{abstract}
Many people suffer from statistics anxiety or helplessness in the UK; this is true even in the context of $\mathrm{PhD}$ students studying at prestigious universities. There is a risk that anxiety or helplessness results in students avoiding engagement with statistics, and consequent underachievement. Here, we illustrate the application of the construct "statistical resilience" to developing positive engagement in statistics. We used the method of a collaborative phenomenological study. The collaboration is between a researcher and a $\mathrm{PhD}$ student acting as a research assistant. The relevant concepts include learned helplessness, self-agency and statistical resilience. As the PhD student gained statistical resilience, he was able to leave behind learned helplessness. This resulted in emancipation from statistical anxiety, an effective contribution to a research project, raised self-esteem and increased ability to engage with formal statistical thinking. The paper ends with recommendations for policy and practice.
\end{abstract}

\section{Keywords}

Statistical Resilience, Statistics Anxiety, Learned Helplessness, Growth Zone Model, Emancipation, Agency

\section{Introduction}

This article is intended to be helpful to anyone seeking to address statistics anxiety or statistics avoidance, or indeed spreadsheet avoidance, as a learner, as an educator or a parent. We seek to provide insights into what can promote and 
support development of statistical resilience.

There is world-wide difficulty recruiting statistical thinkers, particularly in social sciences in the UK. This study illustrates that statistical avoidance and helplessness can be addressed quickly and effectively. This article presents an illustrative phenomenological study of a PhD candidate (Hani) and a change in the relationship of this candidate with statistics arising from an interaction with a researcher who is also a teacher of statistical resilience (Sue). We present an individual, but illuminating, study which describes Hani as he recalls learning to feel helpless in relation to statistics and then, through interaction with Sue, acquires statistical resilience, overcoming the learned behaviour of helplessness through "ordinary magic" (Masten, 2001). The notion of statistical resilience arises from previous work on mathematical resilience (Johnston-Wilder \& Lee, 2010; Lee \& Johnston-Wilder, 2017) which demonstrates that effects of previous negative experiences can be overcome and transformed into productive interactions.

\section{Key Concepts}

One of the key concepts for this study is that of everyday statistics. Concept formation happens at two levels-the everyday and scientific (Vygotsky, 1986). Everyday concepts are learned by interacting directly with the world-developing intuitive understandings. In this sense, everyone uses everyday statistical thinking, even in utero, but may not be aware of it, developing sensory experience of distributions such as volume, tone and quantity, comparing, contrasting and learning to make decisions. Vygotsky (1986) argued that everyday concepts should be the foundation for the concepts in school science which he called scientific concepts. Everyday concepts are based on particular experiences and are not yet built into a coherent system of thought; scientific concepts are presented and learned as part of a system of relationships. However, scientific concepts are often taught separated from familiar contexts, leaving the learner unable to apply them, which, in a contrasting process, can leave the learner feeling unable to proceed with new knowledge in this area.

Another key concept is transformational learning (Mezirow, 2000), often described as learning that changes the way individuals think about themselves and their world, involving a shift of consciousness. Central to transformational learning are acceptance, empathy, and trust (Mezirow, 2000). Further, adult learners tend to be self-directed, problem-centered and wanting to apply new learning immediately (Knowles, 1980). This means that adult learners will be better able to assimilate new knowledge and more likely to use transformational learning to achieve their immediate goals when they are secure in current knowledge, when their learning is directed toward a concrete goal, and when they feel supported by those around them or directing/supporting their learning. Research has shown that success in such encounters engenders feelings of self-efficacy and the ability to tackle new problems (Bandura, 1977; Goodall \& 
Johnston-Wilder, 2015).

In a previous paper (Goodall \& Johnston-Wilder, 2015), the links between the concepts of learned helplessness, self-agency, mathematics anxiety and mathematical resilience (Johnston-Wilder \& Lee, 2010) were examined in the context of supporting maths at home for a school-based student. In this paper, we reprise the concepts and their links, relating them to adult learners and to statistics.

\subsection{Learned Helplessness and Self-Agency}

People who have experienced harmful situations in the past where they have not been able to adapt productively or escape may develop "learned helplessness" (Abramson, Seligman, \& Teasdale, 1978; Seligman, 1972). This includes harmful past experiences of statistics. It is important here to note that harm may include social harm such as humiliation or exclusion (Siegel, 2010).

Once a belief is established that no action on the learner's part can change the outcome of engaging with an area of study such as statistics, the learner becomes much less likely to try (Hallinger, 2011). Thus it is important to work with what the learner can control, that is, to enable the learner to notice and develop their self-agency (Bandura, 2000); it is this control that allows someone to overcome their passivity (a feeling such as, "I can't do it") in the face of stressful events (Maier \& Seligman, 2016). Emirbayer and Mische (1998) conceptualize human agency as "a temporally embedded process of social engagement, informed by the past... but also oriented toward the future (as a capacity to imagine alternative possibilities)" (p. 963). So the learner needs to build on a positive, or positively understood past (if necessary re-framed) to envision and bring to fruition a positive present and future.

\subsection{Statistics Anxiety}

A large proportion of adult students identify statistics courses as the most anxiety-inducing courses in their curriculum (Zeidner, 1991; Paechter et al., 2017). Ashcraft defines mathematics anxiety as "a feeling of tension, apprehension, or fear that interferes with math performance" (Ashcraft, 2002: p. 1). This phenomenon is prevalent in the branch of mathematics known as statistics. In this article, we take statistics anxiety to be closely related to, but not identical with, mathematics anxiety (Chew \& Dillon, 2014). It is significant that many of the studies of statistical anxiety deal with university students (who are arguably adults) rather than young people still of school age. This allows us to see how knowledge about adult learning can applied to overcoming this form of anxiety. For this purpose, we use the definition offered by Chew and Dillon: "a negative state of emotional arousal experienced by individuals as a result of encountering statistics in any form and at any level; this emotional state is preceded by negative attitudes toward statistics and is related to but distinct from mathematics anxiety." (Chew \& Dillon, 2014: p. 199). Students studying statistics may ex- 
perience feelings of discomfort and negative cognitive reactions experienced by (Chew \& Dillon, 2014). This kind of anxiety may result in hindering performance in statistics and hence in its avoidance, or procrastination (Paechter et al., 2017; Onwuegbuzie, 2004). Statistical anxiety can be envisaged as "a particular form of performance anxiety characterised by extensive worry, intrusive thoughts, mental disorganisation, tension, and physiological arousal" (Zeidner, 1991: p. 319). Statistics anxiety is likely to be shaped by a set of affective, social and cognitive factors and caused by past experiences of success and failure in situations involving mathematics established in school years. Research on mathematical resilience resonates with that of Paechter et al. (2017), who advise that statistics instructors should emphasize effort and the value of statistics to help students overcome the impact of statistics anxiety. However, we also argue that more can be done by raising awareness of the role of anxiety and the learner's brain more explicitly, particularly with adults, for whom agency in learning is paramount. This will allow the learner to create the emotional regulation necessary to engage with statistical work.

A hand model of the brain, Figure 1, was developed by Siegel (2010). It presents a psychological strategy that helps to self-regulate feelings and thoughts so that the learner can create time-out space to tackle fears when faced with an unfamiliar predicament and hence activate problem-solving skills. Responding to a stressful situation, this model draws an analogy between the hand and the brain. The wrist represents the brain stem which keeps us safe. The thumb folded across the palm represents the middle part of the brain (midbrain) where we process emotions, store memories, and have our "safety radar". The fingers folded over the thumb represents the outlier of the brain (the cortex), the part of the brain where we think and plan our lives. Fingernails represent the area of the brain that is right up front (prefrontal cortex), where the brain processes information

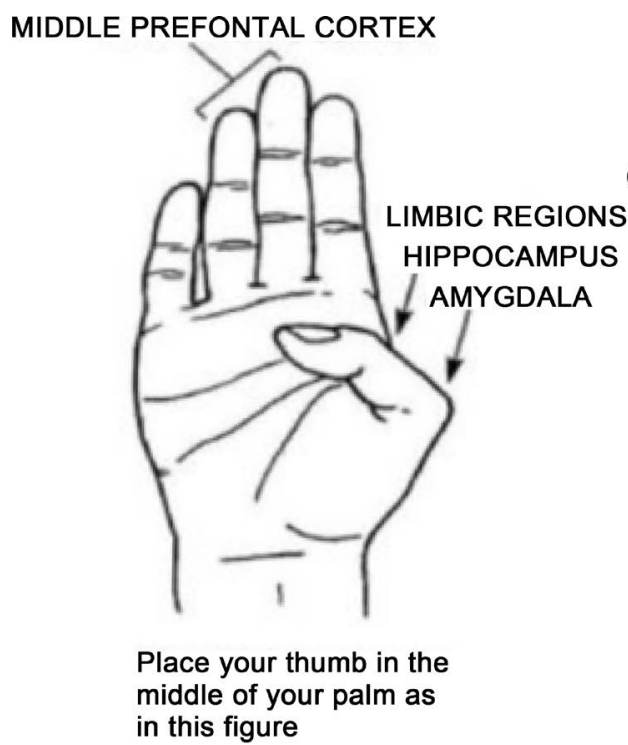

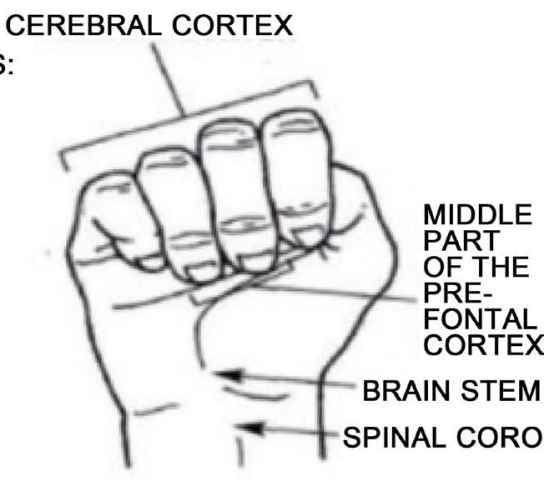

Now fold your fingers over your thumb as the cortex is folded over the limbic areas of the brain

Figure 1. The hand model of the brain (Siegel, 2010). 
about how we relate to our social world (solve problems, understand others' feelings and mental states). Finally, lifting our fingers up represents something called "flipping our lid" where a person feels stressed and therefore their brain (prefrontal cortex) freezes or stops working with the rest of our brain and hence they neither think effectively nor problem solve. One can see the connection between "flipping one's lid" and the anxiety which arises from encounters with maths/statistics; the reactions of passivity and withdrawal which result from this anxiety are clearly like those which result from "flipping one's lid". This means that Siegel's model of the brain may be useful in understanding, and overcoming, statistics anxiety.

\subsection{Resilience}

Resilience enables students to deal with difficult situations, which might otherwise affect them adversely or be disabling, and allows them to find and use "adaptive outcomes" to such situations (Waxman, Gray et al., 2003: p. 2). Williams (2014) describes resilience as being a combination of confidence, persistence and perseverance. Resilience includes agency on the part of the learner, agency which has been described as a "struggle" (Waxman, Gray et al., 2003: p. 2); in Williams' version the agency is found within both persistence and perseverance. From any starting point, resilience can be learned, enhanced and promoted by a focus on that which can be altered by the learner, so that pupils become better able to confront and overcome obstacles. This necessarily requires, however, that the learner has moved away from the passivity which is engendered by feelings of helplessness.

Four attributes are generally exhibited by resilient people: social competence, problem solving skills, autonomy and a sense of purpose (Benard, 1991). The work of Dweck adds the importance of a growth mind-set to this list. Masten (2001), amongst others, suggests that a learner's environment can support the development of resilience, particularly within the classroom, the peer group and the family.

\subsection{Statistical Resilience}

Johnston-Wilder and Lee (2010) have proposed that we use generic understanding of what builds resilience in general and academic resilience in particular to help address mathematics anxiety. They constructed the term "mathematical resilience; and we here extend the term to specifically include "statistical resilience" as a subset of "mathematical resilience". Many students experience statistics as excluding, if not upsetting, and develop avoidance. However, students who develop statistical resilience come to believe they can also develop statistical ability. They come to feel included, thinking of themselves as already able to think and reason statistically. Bandura uses the term "resilient self-efficacy" (Bandura, 1994). Thus, if a student with statistical resilience encounters statistics that they are not yet able to comprehend, they will invest effort, seek support 
and expect to learn new skills in appropriately sized steps. They will access the internet, or talk to a colleague they trust. They will know about the need to connect to existing knowledge and understanding, and know and expect to use Bruner's ladder of accessibility: enactive-iconic-symbolic (Bruner, 1966), if necessary creating physical artefacts to access concepts. This accords with the nature of adult learners as self-directed agents of their own learning, as discussed above.

Figure 2 is a visual representation of what Johnston-Wilder and Lee have called the growth zone model. Figure 2 suggests three "zones" or ways of experiencing learning from the point of view of the learner. In the central, comfort zone (often depicted green), the learner feels safe when dealing with problems on his own; he is able to use current knowledge to good effect and does not experience stress in relation to working in mathematics. The outermost zone, the danger zone (often depicted red), is experienced as a polar opposite, as a place of great stress and lack of security and self belief. This area is dangerous to the learner, as he is unable to navigate it safely. Learners in this zone, which can differ from person to person, experience a "fight, flight or freeze" reaction, that is, a desire to battle against (rather than engaging with), or flee from the obstacle, or an inability to react cogently at all.

Between these two zones lies the "growth" zone (often depicted amber), which is related to Vygotsky's “zone of proximal development" (see Zaretskii, 2009). Remaining in the comfort zone feels safe to the learner but, for many, this is unlikely to result in the acquisition of new knowledge or skills; moving directly to the danger zone on the other hand, is also unlikely to result in new knowledge or skills, as the flight, fight or freeze reaction induced by this zone is not conducive to learning. It is in the growth zone that the learner will experience optimal growth (see also Zaretskii, 2009). The growth zone affords enough challenge to learn, a willingness to take managed risks and learn from mistakes; it goes hand in hand with the support of being part of a learning community that encourages the asking of questions and helps prevent the learner from disengaging or being unable to engage with learning.

\section{Methodology}

In this paper, we present an illustrative phenomenological study of Hani, a

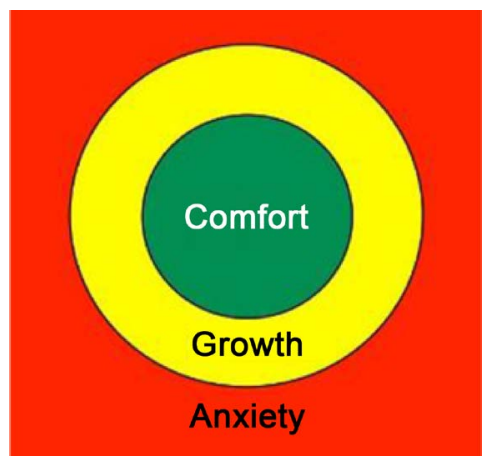

Figure 2. The growth zone diagram. 
primary school teacher and end-stage $\mathrm{PhD}$ student, who presents initially with severe statistics anxiety, and overcomes it. This study is phenomenological in that we seek to understand the essence of Hani's experiences. "Phenomenology is the study or inquiry into how things appear, are given, or present themselves to us in pre-reflective or lived experience." (Van Manen, 2014). In context of this study, the empirical methods and procedures included written personal descriptions of experiences, interviewing for experiential accounts and observing. Reflective methods include auto-biography and collaborative reflection. In that it is a collaborative work with Hani, the study is in part auto-ethnographic; Cranton (2002) suggested the use of autobiographical accounts to promote engagement in reflective discourse and analysis of assumptions. Hani engages in self-reflection and writing to explore his personal experience and to connect his story to wider cultural, political and social concerns. It is also a study in transformational learning, expressing vulnerability, experiencing empathy, fostering self-empathy, and honouring subjectivity (Custer, 2014).

One of the central ideas of phenomenological methodology is that it focuses on the lived experiences of the researched from the perspective of the people involved (Groenewald, 2004); the meanings they ascribe to these experiences can be shared. While one may not be able to generalise widely from such individual studies, the lessons learned can be more widely applied. Our emphasis here is on the phenomenon of learned statistical helplessness and anxiety, and on providing a trustworthy description of Hani's experience of working with Sue; we present Hani's experience as demonstrating elements typical of statistics anxiety. We also seek to explain and to understand Hani's experience of becoming resilient, as he stepped out of his comfort zone when he started, willingly and with support, to undertake tasks that were beyond his knowledge and comfort. When working with people with anxiety, we have found it helpful to invite people to start by telling their story to-date (Johnston-Wilder and Marshall, 2017). Hani wrote a reflective piece about his early experiences with mathematics and statistics, which we introduce below.

\section{Hani's Experience of Statistical Anxiety}

Hani recognised that avoidance of maths is not innate, illustrating his early, natural, everyday use of mathematics and statistics (Vygotsky, 1986): As a kid, I used to play with children of different ages in the neighbourhood. Our play contained different games, such as skipping, playing with stones, hide and seek, football, which included simple mathematical processes, such as counting the stones, adding, subtracting, or keeping a record of the scored goals.

Hani recognised that support was needed, and available, during elementary school. He described his early experience of thriving in school mathematics and recruiting support when needed: Elementary school in my country starts at 6 and ends at age 12. During this period, I would rate my math level as average, as I was getting some help from my brother( $(s)$. Normally, one teacher teaches all 
the subjects throughout the school year. So at this stage, my mathematics was good and I was active and comfortable in this area as I was able to solve the assignments almost on my own. When faced with a difficulty, I would ask a brother to help me.

Hani described the impact of increased abstraction, lack of support, and how he used what resources were available to him: At age 12, when I moved to the preparatory school, there was a huge gap between the mathematics that I was studying at the primary school and the new one at this school. The mathematics at the preparatory school started to be more specialised and abstract (i.e., algebra and geometry). During the first term of my first year at the preparatory school, the maths teacher was absent for almost two months. I started to experience difficulty in maths as my self-efficacy in solving math problems started to degenerate. During my three years in the preparatory school, I received no help from my siblings, my parents or my relatives. My older brothers were not into math subjects, they were more into arts such as geography, history, and Arabic literature. Having difficulty with maths during this stage of my school, I had little source of help to turn to-the teacher had 33 students and tended to focus on progression of the most able. I was trying hard to follow the maths teacher's lead and to understand the nature of the mathematical problems that they would assign to us. Sometimes I chatted informally with my peers, [in] the main my peers were experiencing similar helplessness. It was like putting a novice swimmer into the sea-the maths felt way above my abilities. The environment was competitive so the higher achieving students did not wish to help us. Sometimes I turned to my siblings' historic maths exercise books to understand and solve maths problems. So I was somehow able to carry on with maths and keep achieving good but not high scores (for example, 30 out of the total score 60). Maths was a chore.

Hani described how he increasingly resorted to memorising techniques: The third year (when I was 14 - 15) included a national exam set by the education ministry and every student had to undertake it in order to move to a secondary school depending on scores. I resorted to some new strategies to help me with maths. I listened even more carefully to what the maths teacher said and paid attention to her explanation in the algebra area, but when it came to geometry, her explanation was not enough for me to understand. So I was struggling with geometry, so I was memorising the geometry theorems, which was my second strategy, without understanding. The third strategy was consulting my brothers' maths exercise books to find out solutions to assignments that I could not solve on my own. In the final exam, I managed to achieve above the pass score (18); I achieved 30 out of 60 . So, algebra and geometry were difficult. I found teachers quickly go through the tasks without extra explanations and illustrating activities. This issue was further exaggerated by having no source of support at home.

Note that avoidance of mathematics in general and statistics in particular sets in, as a pro-active coping strategy: Aged 15, I started my secondary school on a general course which would allow me to go to University. So the first year in- 
cluded a mix of mathematics (algebra and geometry), sciences, languages and arts, to accommodate students of both maths/sciences and arts interests. At the start of the year, I started thinking of choosing a field that did not involve maths in any way.

During the first year, I was feeling that the gap and discontinuity started to become so huge that I was no longer able to handle maths, not even the assignments in this area. So all I did was copying homework from either a friend or my brother's exercise book. I attended all maths classes without missing one. However, during these classes I felt that the teacher was talking a language, a totally foreign one, which I was not able to understand, grasp, or contribute to. Here, I started to experience maths alienation; I was a passive student at these classes.

Finishing the first year of the secondary school, I chose to carry on my education in a field with no maths, so I chose the arts route. So I did my National Examination in arts and I got good grades that enabled me to go to a university, where I chose to carry on my studies at a faculty where there was no maths at all. I took a first degree in Education and Curriculum. There was just one module in Statistics. The teacher encouraged us to ask any questions we wished to and to keep repeating those questions until we understood. My peers had a background in struggling with maths also. I could understand the statistics most of the time. I nagged my brother's friend to help me with things that I had forgotten-he was studying engineering. I passed that module with $75 \%$. Thus, if I could recruit the right support I was able to progress, but without that additional support I felt anxious and depressed due to helplessness.

Note that Hani continued to persevere, to seek support where he could, with some success: After that I avoided maths as much as possible. I worked as a cover primary school teacher, avoiding teaching maths. I was employed at a University as a teaching assistant, and was comfortable continuing to avoid the maths. I gained a scholarship and undertook a Masters and PhD at Warwick; and used only descriptive statistics which I undertook by hand. I avoided using Excel-the cells didn't make any sense to me. I attended an SPSS programme because I believed it might be helpful in my PhD but I could not understand more than the descriptive statistics. The pace of the course was too fast and the lecturers did not feel able to make provision for anxious slower learners.

Hani was not aware of any alternative forms of support. Since 2003, he was not able to recruit the support he needed to make progress and became statistics-avoidant in practice. In discussion about his experience, Hani drew a diagram to represent his avoidance (see Figure 3 ).

As part of the process of reflecting collaboratively on his prior experience, Sue introduced Hani to: the notion of helplessness, the hand model of the brain, the growth zone model and Williams' (2014) characterisation of resilience as a combination of confidence, persistence and perseverance (which involves recruiting resources and support). Regarding learned helplessness in relation to statistics, Hani described experiencing specific internal helplessness. He felt convinced that no further effort on his part would bring about success, but only in relation 


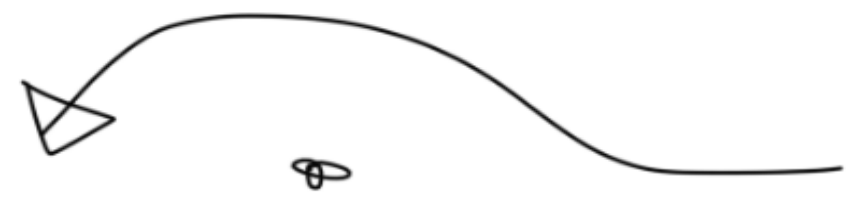

Figure 3. Hani's drawing of his reaction to statistics before the intervention, representing him deviating from his path to go round and avoid the statistics.

specifically to statistics; his helplessness did not spill over into other areas of life. Further, the issue resided not in the subject of statistics but in the agent attempting to overcome his difficulties; the helplessness was internal. In other words, Hani did not perceive the maths to be "too hard", but rather perceived himself to be "incapable" of dealing with the subject, having internalised a helpless frame of mind. In case of Hani, his past experiences with mathematics were conducive to his subsequent feeling of anxiety with statistics. Hani recognised himself as having started out perseverant (Williams, 2014), in that he recruited whatever support he could. At school, as the level of maths was growing in complexity and abstraction, and support was not accessible, he resorted to instrumental learning (Skemp, 1976) rather than deep, relational understanding. Ultimately, he withdrew from statistics and subsequently became actively avoidant, in order to protect himself from the experience of panic. Hani had global resilience; he was capable of undertaking a $\mathrm{PhD}$, an enterprise which calls for autonomy, problem solving skills and a sense of purpose, and social competence, all in a second language in an unfamiliar country. He did not yet have resilience in relation to statistics, and so that was in need of development.

\section{Hani's Experience of Developing Statistical Resilience}

For Hani, his school experience and his community were not environments for the development of (statistical) resilience; on the contrary, he developed learned helplessness and also anxiety, that is, he gave up any concept of agency in relation to the learning of statistics. Rather, it was through his interaction with a more knowledgeable other (Vygotsky, 1986), that the key to resilience was found, and once found, was reinforced through purposeful, valued project involvement and support.

Hani knew that Sue was working on mathematics education and, experiencing acceptance, empathy, and trust (Mezirow, 2000), he took the opportunity to talk about his experience. Up to that point, he had been feeling he could do nothing in relation to maths (whether algebra, statistics, geometry). He had always wanted to be good at maths. In conversation, Sue used the expression "maths-excluded" and Hani identified with this term. He recognised himself as wanting to develop his statistics skills. Two things resulted from that conversation: Sue invited him to join the team working on a research project developing mathematical resilience in $\mathrm{FE}$, as a research assistant, and she advised him to 
read an introductory book to statistics: developing thinking in statistics (Graham, 2006) which had been specially written for teachers who were being asked to teach lower secondary maths. Thus it took an approach appropriate to adult learners.

For the research project, Hani, supported by Sue, took the first step towards overcoming his maths exclusion by starting to use Excel, although in a very limited way, to work with larger amounts of data descriptively, building links with his existing knowledge of qualitative research. Before having this opportunity of being involved in a project that required statistical skills, Hani had found no access to support. He felt increased self-efficacy in relation to Excel, finding it was manageable and understandable with some effort.

Reading and reflecting on the book, Hani became aware that he was not, in fact, excluded totally from statistics. Even though he thought he was avoiding statistics, he was actually making use of it daily, e.g. when watching a football team he would consider their chances of winning; he often would say "it is highly likely that team $\mathrm{X}$ will win the game". He was making guesses (i.e., extrapolation) based on his best knowledge about the dynamics of the match and actions of the players. He realised he had included himself in statistical thinking at a low level but he wanted more. He came across many concepts that he was using in his everyday activities without being aware of that. Even in his academic studies at school and university, he was making best guesses regarding his marks and achievements, based on his knowledge of his performance and preparations. Through reflection on his mindset, he started to develop the awareness that there was no longer a reason to stay away from statistics or feeling "I cannot do it”. His attitude started to change especially so when he came across the research cycle in quantitative research, which bears lots of similarities to qualitative research with which he was familiar.

Overall, his mathematics and statistics ability throughout the exclusion experience resembles to some extent that of a seed in the desert waiting for the rain. During his $\mathrm{PhD}$ studies he had attended SPSS courses which were challenging and, especially, many of the terms used were new and unclear. Hani found it helpful to describe previous attempts using the hand model of the brain: he would "flip straight away", experience his brain as offline and be unable to calm himself. He was unable to focus, to think about the statistics and got left behind. He would leave before these sessions ended and walk away.

Starting the apprenticeship in the project where he started reading the introductory book to statistics and watching videos on YouTube illuminating some SPSS uses, he started to develop understating of statistics. Some concepts became no longer alien, such as regression, correlation, means and median. He already knew about variables in a qualitative way but now he understood how these can be measured and was willing to deepen his understanding of these processes and use resources to grow in this area. Now he felt he had become "a real beginner"; he moved from a situation where any subject containing statistics was experi- 
enced with panic and helplessness, to a situation where he was willing to engage in solving statistics problems drawing on his skills, resources and support; he became more resilient. Hani described his new statistical functioning as willingness to undertake statistics-related activities. He moved from total statistics avoidance to thinking that statistics can be dealt with when putting some effort if he could recruit support and manage his panic. He attended an SPSS beginner course for the sixth time: This time [when my brain] started to go offline, I asked questions, I was quicker, because of the book and the project. This time I found it was more like something understandable. This time the data was similar enough to the project data which enabled me to understand and access what I had learned.

During his final reflection with Sue, Hani expressed annoyance at feeling like a child in relation to statistics. He said, I should have known that before. It is not difficult. I just needed this flip, tip, quick experience to help and I didn't get it when I needed it. I feel stupid about it, a bit sad that I didn't learn it before. But we need to remind ourselves that young learners are not stupid-far from it. They have curious brains that are also highly protective, with a safeguarding mechanism that is highly tuned to avoid perceived danger and to fight or flee when it is perceived (Siegel, 2010). Danger here includes social threats such as humiliation, exclusion and being left behind.

In the past, Hani would give up when his brain went offline in panic and he became unable to think clearly. Now he is able to address the panic effectively, and bring his brain back online quickly. Now he is able to ask questions in sessions and access YouTube to cover aspects he may have missed whilst he was bringing his brain back online. Now, he is attempting to continue to develop statistics and also maths skills by reading more in this area and by carrying out research that requires such skills. He is now aiming to teach primary mathematics in the medium term.

\section{Discussion}

We seek access to the lived experience of statistical anxiety, avoidance and resilience, hoping that the meanings "brought to the surface from the depths of life's oceans have not entirely lost some of the natural quiver of their undisturbed existence, as Merleau-Ponty might say." (Van Manen, 2014).

"[O]ne needs to realize, of course, that experiential accounts or lived experience descriptions are never identical to lived experience itself. All recollections of experiences, reflections on experiences, descriptions of experiences, taped interviews about experiences, or transcribed conversations about experiences are already transformations of those experiences". (Van Manen, 2014).

Hani's description of the process of becoming excluded and avoidant around statistical work is vivid. It is a process that occurred over extended time. Hani 
described as he remembered it the impact of increased abstraction, lack of support, and how he used what resources were available to him. He described how he increasingly resorted to memorising techniques and how he began strategically to avoid statistics and manage as best he could, and how he experienced anxiety that he was unable to address when he was not able to avoid. Such processes are historically well documented (Skemp, 1976; Bruner, 1966). When people meet obstacles, they can give up trying because they lack self-efficacy, or they may start out with self-efficacy but give up trying because they experience their actions having no effect or consistent punishment or embarrassment (Bandura, 1977). Johnston-Wilder and Lee (2008) have discussed what they term "mathematical abuse", which causes "damage to the way pupils think about mathematics and to their ability to succeed in learning mathematics" (p. 56). If we accept the term "abuse" in relation to the outcome (if not the intention), then it is clear that Hani suffered this in relation to his ability to "do" statistics; his agency, his self-efficacy and belief in his ability to grow the skills necessary to solve problems, had been severely undermined. "I think, in my case, the issue was personal since I felt I lacked any support in this regard and at the same time I knew that I would be able to do well in statistics, had the support become available." (Hani, interview notes)

In relation to the concept of "learned helplessness", what is learned is that outcomes are uncontrollable (Abramson \& Sackheim, 1977; Abramson, Seligman et al., 1978), which Hani reports from his early experiences, "teachers' fast paced explanations of... problems" and when mathematics and statistics started to grow in abstraction where self-study was not enough. Hani came to believe that problems were beyond his reach to solve. Hani experienced specific helplessness in relation to statistics. Hani found coping mechanisms for his issues with statistics, minimising contact and recruiting support from his $\mathrm{PhD}$ peers where statistics were unavoidable, and was able to complete a qualitative $\mathrm{PhD}$. Individuals are able to function well in some areas of life, while presenting an attitude of helplessness in others (Singer, 2012).

In terms of Hani's statistics experience, he used to "flip out" once faced with any statistical problem; becoming stressed, anxious and helpless. Hence, with such learned response to statistics, he would automatically choose to avoid it as he would have "flipped". Lacking skills and the high level of abstraction along with the absence of support were the main reason he would have flipped. Based on the growth zone model, he learned that approaching statistics need not be this way. Sue encouraged him to take time to think why he felt helpless when it came to statistics problems. Being introduced to the growth zone model, he learned that skills can be stretched and rebuilt. And his participation as a research assistant in the FE mathematical resilience project offered him time to work on developing his knowledge and skills with statistics and hence to improve his experience with statistics. Throughout the project, meeting with Sue created focused opportunities to calm down, reflect and to discuss fears and 
ways forward, maintaining agency as an adult learner, within a supportive environment.

This learned helplessness was systematically tackled when Hani started to feel included in statistics. Sue made it clear that lacking knowledge and skills in statistics was not a reason to be excluded, as learning in this area could advance with effort and support. She spoke about and modelled a growth mind-set. She conceived of Hani as already being a statistical thinker, shared with him the growth zone model (see Figure 2) and made him aware of the importance of asking questions when stuck, remaining or recovering calm and using his abilities to learn. Unlike the past environment that led him into responding to statistics with helplessness and avoidance, these actions created a supportive, inclusive environment where support and resources for developing higher level statistical thinking were at his disposal. Hani found it helpful to access YouTube tutorials and to apply the new statistical ideas to the project data with which he was familiar. Hani developed statistical resilience; we illustrate this movement in Figure 4 below.

The growth zone model offers valuable insights to learners and staff, and goes some way towards providing a remedy for the negativity and failure previously experienced. A strategy that is focused on the development of statistical resilience in staff and their students may thus offer hope of progress. Such a strategy requires focus on each of the elements that together make up the concept of mathematical and statistical resilience: growth mind-set, effort, support, inclusion.

This small scale exploration accords with recent research showing evidence that specific anxiety is treatable (Jamieson et al., 2010; Park et al., 2014). For example, Park et al. asked 80 students of varying mathematics anxiety either to sit quietly (control group) or to write about their worries in relation to mathematics; the study showed that writing about performance worries may free up working memory resources, helping students better to identify, differentiate, and understand their emotional experiences, which can lead to the adoption and execution of more effective strategies to regulate emotions.

We conclude the study with suggestions for further research, as well as

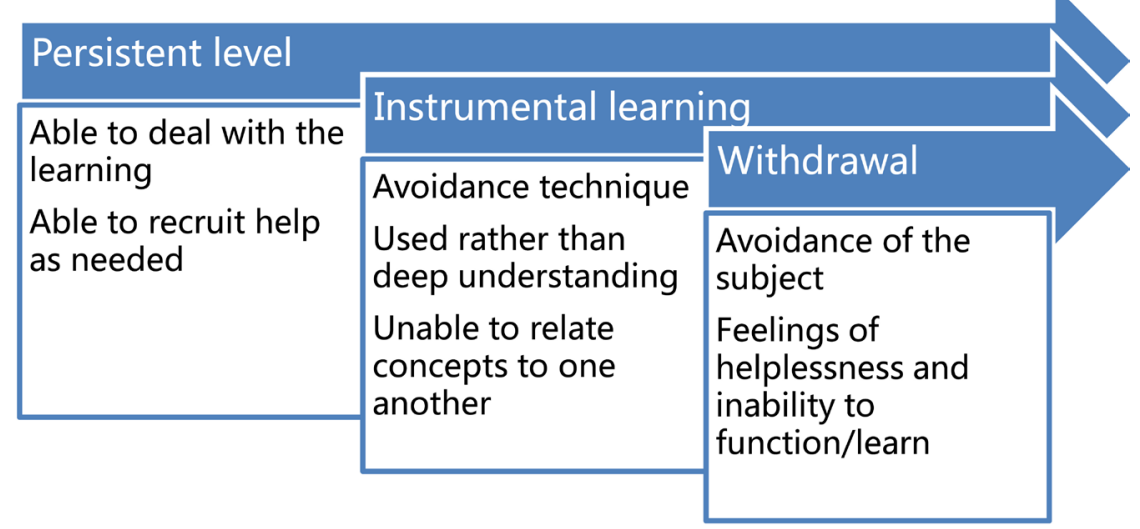

Figure 4. Progress of anxiety. 
recommendations for universities in relation to supporting students, including $\mathrm{PhD}$ students, and a caveat around the use of the term "resilience".

\section{Implications and Recommendations}

"All social research sets out with specific purposes from a particular position, and aims to persuade readers of the significance of its claims; these claims are always broadly political" (Clough \& Nutbrown, 2007: p. 4). In this article, we seek to explore the "taken for granted" experience of statistics anxiety and work towards critique and action that leads to learner emancipation from statistics anxiety. Thus our goal in writing up these experiences is to illustrate the process of becoming excluded from statistics and avoidant and of the transformation that is becoming statistically resilient. We seek to challenge the notion that statistical thinking is inherently difficult. We seek to enable more thought about how to make statistics more accessible.

Hani described the impact of increased abstraction, lack of support, and how he used what resources were available to him. He described how he increasingly resorted to memorising techniques and avoidance of mathematics in general and statistics in particular. Hani has also described the impact of the hand model of the brain, learning to calm himself, building a connected understanding of statistical terms, accessing YouTube tutorials for specific concepts, asking questions and applying the new statistical ideas to the project data with which he was familiar. Teachers might make much more use of such internet resources.

We recommend that readers, teaching institutions and teachers recognize the possibility of transformative effects of statistical resilience for all students, and seek to support its development. We believe that it is in the nature of adult learners to seek improvement, whilst staying safe from perceived threats. In dealing with learners who have already acquired a specific anxiety, we commend the hand model of the brain, the growth zone model and learning how to calm (the relaxation response; Benson, 2000). We recommend introducing these concepts to all learners, so that they may be enabled and empowered to re-engage, self-safeguard and have a clear understanding of what effective engagement in learning statistics entails. Learners should be able to expect accessible, inclusive resources, support, and inclusion as a member of a research team working on a project of personal value.

We include here a caveat about the term "resilience". We have described a process by which one learner has become "resilient" in the face of previous feelings of inadequacy and helplessness. However, we do not wish our description of this successful process to mask, or to obscure, the more fundamental issue at play here, which is the inculcation of such feelings in the first place. It is very easy to advocate that students should become "resilient" and able to support their own learning, without talking about the fact that such resilience is only necessary in the face of induced feelings of helplessness and inadequacy. In this case, Hani developed these feelings after a succession of experiences which led to 
feelings of alienation and exclusion-feelings which did not need to arise. While we advocate the ideas outlined here to support students already experiencing helplessness, we do not wish to underestimate the number of students who do not overcome such feelings, nor yet to ignore the fact that these feelings have been caused by what Johnston-Wilder and Lee (2008) have termed mathematical abuse. The impetus should not lie with the student to "become resilient" in the face of abuse, but rather on the system, to avoid the need for such resilience in the first place.

In Hani's words: re-inclusion is like healing a broken leg. Teachers can provide the leg with the conditions to make it heal, fostering inclusion, encouraging independence, recognizing existing strengths and weaknesses, creating an environment where it is safe to ask questions, building confidence, persistence and perseverance, understanding the role of anxiety in self-safeguarding and helping the learner stay within their growth zone. Many teachers already know how to teach like this but are themselves anxious about statistics-these teachers need to be enabled to develop their own statistical resilience. This paper has the potential to provide helpful insights into what can promote and support development of statistical resilience in all students.

\section{References}

Abramson, L. Y., \& Sackheim, H. A. (1977). A Paradox in Depression: Uncontrollability and Self-Blame. Psychological Bulletin, 84, 838-851.

https://doi.org/10.1037/0033-2909.84.5.838

Abramson, L. Y., Seligman, M. E., \& Teasdale, J. D. (1978). Learned Helplessness in Humans: Critique and Reformulation. Journal of Abnormal Psychology, 87, 49-74. https://doi.org/10.1037/0021-843X.87.1.49

Ashcraft, M. H. (2002). Math Anxiety: Personal, Educational, and Cognitive Consequences. Current Directions in Psychological Science, 11, 181-185. https://doi.org/10.1111/1467-8721.00196

Bandura, A. (1977). Self-Efficacy: Toward a Unifying Theory of Behavioral Change. Psychological Review, 84, 191-215. https://doi.org/10.1037/0033-295X.84.2.191

Bandura, A. (2000). Exercise of Human Agency through Collective Efficacy. Current Directions in Psychological Science, 9, 75-78. https://doi.org/10.1111/1467-8721.00064

Bandura, A. (1994). Self-Efficacy. In V. S. Ramachaudran (Ed.), Encyclopedia of Human Behavior (Vol. 4, pp. 71-81). New York: Academic Press. [Reprinted in H. Friedman (Ed.), Encyclopedia of Mental Health. San Diego, CA: Academic Press, 1998]

Benard, B. (1991). Fostering Resiliency in Kids: Protective Factors in the Family, School and Community. San Francisco, CA: Far West Laboratory for Educational Research and Development. ED 335 781. https://files.eric.ed.gov/fulltext/ED335781.pdf

Benson, H. (2000). The Relaxation Response. New York, NY: HarperCollins Publishers.

Bruner, J. S. (1966). Toward a Theory of Instruction. Cambridge, MA: Harvard University Press.

Chew, P. K., \& Dillon, D. B. (2014). Statistics Anxiety Update: Refining the Construct and Recommendations for a New Research Agenda. Perspectives on Psychological Science 9, 196-208. https://doi.org/10.1177/1745691613518077 
Clough, P., \& Nutbrown, C. (2007). A Student's Guide to Methodology (2nd ed.). London: Sage Publications.

Cranton, P. (2002). Teaching for Transformation. In J.M. Ross-Gordon (Ed.), New Directions for Adult and Continuing Education: No. 93. Contemporary Viewpoints on Teaching Adults Effectively (pp. 63-71). San Francisco, CA: Jossey-Bass.

Custer, D. (2014). Autoethnography as a Transformative Research Method. The Qualitative Report, 19, 1-13. http://nsuworks.nova.edu/tqr/vol19/iss37/3

Emirbayer, M., \& Mische, A. (1998). What Is Agency? American Journal of Sociology, 103, 962-1023.

Goodall, J., \& Johnston-Wilder, S., (2015). Overcoming Mathematical Helplessness and Developing Mathematical Resilience in Parents: An Illustrative Case Study. Creative Education, 6, 526-535. https://doi.org/10.4236/ce.2015.65052

Graham, A. (2006). Developing Thinking in Statistics. London: Sage.

Groenewald, T. (2004). A Phenomenological Research Design Illustrated. International Journal of Qualitative Methods, 3, Article 4.

http://www.ualberta.ca/ iiqm/backissues/3_1/html/groenewald.html https://doi.org/10.1177/160940690400300104

Hallinger, P. (2011). Leadership for Learning: Lessons from 40 Years of Empirical Research. Journal of Educational Administration, 49, 125-142.

https://doi.org/10.1108/09578231111116699

Jamieson, J., Mendes, W. B., Blackstock, E., \& Schmader, T. (2010). Turning the Knots in Your Stomach into Bows: Reappraising Arousal Improves Performance on the GRE. Journal of Experimental Social Psychology, 46, 208-212.

Johnston-Wilder, S., \& Marshall, E. (2017). Overcoming Affective Barriers to Mathematical Learning in Practice. In IMA Conference (online). London: Institute of Mathematics and its Applications.

https://cdn.ima.org.uk/wp/wp-content/uploads/2016/07/Overcoming-affective-barriers -to-mathematical-learning-in-practice-Marshall-Johnston-Wilder-paper.docx

Johnston-Wilder, S., \& Lee, C. (2008). Does Articulation Matter When Learning Mathematics? Proceedings of the British Society for Research into Learning Mathematics, 28, 54-59.

Johnston-Wilder, S., \& Lee, C. (2010). Developing Mathematical Resilience. Paper presented at BERA Annual Conference. Warwick: University of Warwick. http://oro.open.ac.uk/24261/2/3C23606C.pdf

Knowles, M. S. (1980). The Modern Practice of Adult Education: From Pedagogy to Andragogy. Englewood Cliffs: Prentice Hall/Cambridge.

Lee, C., \& Johnston-Wilder, S. (2017). The Construct Mathematical Resilience. In Xolocotzin, \& Ulises (Eds.), Understanding Emotions in Mathematical Thinking and Learning (pp. 269-291). Cambridge, MA: Elsevier Academic Press. https://doi.org/10.1016/B978-0-12-802218-4.00010-8

Masten, A. (2001). Ordinary Magic Resilience Processes in Development. American Psychologist, 56, 227-238. https://doi.org/10.1037/0003-066X.56.3.227

Maier, S. F., and Seligman, M. E. (2016). Learned Helplessness at Fifty: Insights from Neuroscience. Psychological Review, 123, 349. https://doi.org/10.1037/rev0000033

Mezirow, J. (2000). Learning to Think like an Adult. Core Concepts of Transformation Theory. In J. Mezirow, \& Associates (Eds.), Learning as Transformation. Critical Perspectives on a Theory in Progress (pp. 3-33). San Francisco, CA: Jossey Bass.

Onwuegbuzie, A. J. (2004). Academic Procrastination and Statistics Anxiety. Assessment 
\& Evaluation in Higher Education, 29, 3-19.

Paechter, M., Macher, D., Martskvishvili, K., Wimmer, S., \& Papousek, I. (2017). Mathematics Anxiety and Statistics Anxiety. Shared But Also Unshared Components and Antagonistic Contributions to Performance in Statistics. Frontiers in Psychology, 8, 1196. https://doi.org/10.3389/fpsyg.2017.01196

Park, D., Ramirez, G., \& Beilock, S. L. (2014). The Role of Expressive Writing in Math Anxiety. Journal of Experimental Psychology: Applied, 20, 103-111. https://doi.org/10.1080/0260293042000160384

Seligman, M. E. (1972). Learned Helplessness. Annual Review of Medicine, 23, 407-412. https://doi.org/10.1146/annurev.me.23.020172.002203

Siegel, D. (2010). Mindsight: Transform Your Brain with the New Science of Kindness. London: Oneworld Publications.

Singer, M. (2012). Human Behavior in the Prison Environment: Adaptation as Survival. Journal of Diverse Social Work, 3, 53.

Skemp, R. (1976). Instrumental Understanding and Relational Understanding. Mathematics Teaching, 77, 20-26.

Vygotsky, L. S. (1986). Thought and Language (A. Kozulin, Trans.). Cambridge, MA: The MIT Press.

Van Manen, M. (2014). Phenomenology. http://www.maxvanmanen.com/files/2014/07/SAGE-Phenomenology.pdf

Waxman, H. C., Gray, J. P., \& Padron, Y. N. (2003). Review of Research on Educational Resilience. Berkeley, CA: UC Center for Research on Education, Diversity and Excellence. https://escholarship.org/uc/item/7x695885

Williams, G. (2014). Optimistic Problem-Solving Activity: Enacting Confidence, Persistence, and Perseverance. ZDM, 46, 407-422. https://doi.org/10.1007/s11858-014-0586-y

Zaretskii, V. (2009). The Zone of Proximal Development: What Vygotsky Did Not Have Time to Write. Journal of Russian and East European Psychology, 47, 70-93. https://doi.org/10.2753/RPO1061-0405470604

Zeidner, M. (1991). Statistics and Mathematics Anxiety in Social Science Students: Some Interesting Parallels. British Journal of Educational Psychology, 61, 319-328.

https://doi.org/10.1111/j.2044-8279.1991.tb00989.x 